\title{
HAZARD IDENTIFICATION AND RISK ASSESSMENT (HIRA) PADA PROSES FABRIKASI PLATE TANKI 42-T-501A PT PERTAMINA (PERSERO) RU VI BALONGAN
}

\author{
Aristy Yulanda Ambarani, Abdul Rohim Tualeka \\ Departemen Keselamatan dan Kesehatan Kerja \\ Fakultas Kesehatan Masyarakat Universitas Airlangga \\ Email: aristyyulanda@yahoo.com
}

\begin{abstract}
HIRA is a process to identify all risk factor in a company then attempt to quantify the risk and determine whether it is acceptable or not. This study aimed to identify and assess occupational risk in the fabrication plate process, tank 42-T501A, at PT Pertamina (Persero) RU VI Balongan. It is an observational and a cross-sectional study based on research time. The object of this study focuses on PT Pertamina (Persero) RU VI Balongan's fabrication plate, tank 42-T-501A, workers with a total population of 20 people plus 1 safety inspector. Primary data obtained through observations and interviews which afterward presented in the form of tables and diagrams to be analyzed descriptively. The result showed that there were 6 procedures with 24 potential hazards and 24 occupational risks in the fabrication process tank 42-T501A. Based on the result of risk assessment, there are 6 low risk hazards, 6 medium risk hazards, 11 high risk hazards, and 1 extreme risk hazard from the total of 24 hazards in the fabrication plate process tank 42-T-501A. Finally, this study concludes that the dominant risk in the fabrication plate process tank 42-T-501A is high risk (45\%). Examples founded in high risk category are stricken by plate, light exposure of torch, fume exposure of torch, sparks of cutting torch, light exposure of welding, fume exposure of welding, sparks of welding, explosions of sandblasting tube and explosions of sandblasting hose.
\end{abstract}

Keywords: hazard identification, risk assessment, fabrication plate

\begin{abstract}
ABSTRAK
HIRA adalah suatu proses untuk mengetahui adanya suatu bahaya kemudian menghitung besarnya suatu risiko dan menetapkan apakah risiko tersebut dapat diterima atau tidak. Tujuan dari penelitian ini adalah melakukan identifikasi bahaya dan penilaian risiko pada proses fabrikasi plate tanki 42-T-501A milik PT Pertamina (Persero) RU VI Balongan. Penelitian ini merupakan penelitian observasional dan merupakan penelitian cross sectional berdasarkan waktu penelitiannya. Objek penelitian ini berfokus pada pekerja fabrikasi plate tanki 42-T-501A milik PT Pertamina (Persero) RU VI Balongan dengan total populasi 20 orang. Data primer didapatkan melalui hasil observasi dan wawancara yang kemudian disajikan dalam bentuk tabel dan diagram lalu dianalisis secara deskriptif. Hasil penelitian menunjukan bahwa pada proses fabrikasi plate tanki 42-T-501A terdapat 24 potensi bahaya dengan 24 risiko dari 6 aktivitas pekerjaan didalamnya. Berdasarkan hasil penilaian risiko, dari 24 risiko pada proses fabrikasi plate tanki 42-T-501A terdapat 6 jenis risiko kategori low risk, 6 jenis risiko kategori medium risk, 11 risiko kategori high risk dan 1 risiko kategori extreme. Kesimpulan dari penelitian ini adalah tingkatan risiko terbesar pada proses fabrikasi plate tanki 42-T-501A adalah risiko kategori high risk sebesar 45\%. Risiko kategori high risk tersebut meliputi risiko tertimpa plate, paparan cahaya torch, paparan fume torch, percikan api cutting torch, paparan cahaya pengelasan, paparan fume pengelasan, percikan api pengelasan, ledakan tabung sandblasting dan ledakan selang sandblasting.
\end{abstract}

Kata kunci: hazard identification, risk assessment, fabrikasi plate

\section{PENDAHULUAN}

Dewasa ini pertumbuhan dan pembangunan infrastruktur di Indonesia semakin meningkat, banyak dibangun pabrik-pabrik, perkantoran, apartemen, dll. Seluruh proses pembangunan tersebut membutuhkan minyak bumi sebagai bahan bakar dan sumber energi. Minyak bumi tersebut perlu untuk diolah terlebih dahulu untuk dapat bermanfaat sebagai bahan bakar. Macam produk olahan minyak bumi yang dihasilkan dapat berupa bensin, solar, minyak tanah, LPG dll (Kementerian Energi dan Sumber Daya Mineral, 2012). Produk olahan minyak bumi tersebut sangat penting baik bagi industri maupun bagi kebutuhan manusia 
sehari-hari. Oleh karena itu, tidak heran kebutuhan minyak bumi sebagai bahan bakar di Indonesia masih tinggi setiap tahunnya.

PT Pertamina merupakan salah satu perusahaan milik negara yang mampu memenuhi kebutuhan bahan bakar masyarakat Indonesia tersebut. PT Pertamina bergerak dalam eksplorasi, pengolahan dan distribusi bahan bakar. PT Pertamina berupaya memenuhi kebutuhan bahan bakar dengan cara memanfaatkan sumber daya alam yang ada di Indonesia. PT Pertamina memiliki visi menjadi perusahaan energi nasional kelas dunia. Dalam upaya pencapaian visi tersebut PT Pertamina berupaya menghasilkan produksi minyak dan gas semaksimal mungkin. Untuk memaksimalkan kegiatan produksinya, maka dibangun tujuh unit refinery dengan kapasitas produksi yang tersebar di berbagai daerah di Indonesia. Dari ketujuh kilang minyak yang dimiliki PT Pertamina terdapat dua kilang minyak yang berada di Pulau Jawa, tempat di mana pembangunan lebih banyak dilakukan dibanding dengan daerah lain. Salah satu refinery yang ada di Pulau Jawa tersebut adalah PT Pertamina (Persero) RU VI Balongan. PT Pertamina (Persero) RU VI Balongan berada di Propinsi Jawa Barat di mana keberadaannya ditujukan untuk memenuhi kebutuhan minyak dan gas wilayah Jawa Barat dan sekitarnya termasuk daerah Jakarta sebagai Ibu Kota Negara.

Saat melakukan proses produksi salah satu komponen penting dalam unit refinery seperti di PT Pertamina (Persero) RU VI Balongan adalah tanki minyak. Dalam unit refinery, tanki minyak berfungsi untuk menyimpan, menampung atau menimbun minyak mentah, produk hasil pengolahan serta produk hasil blending. Untuk dapat tetap berfungsi dengan baik, benda yang terbuat dari plate baja ini perlu untuk dilakukan perawatan dan perbaikan. Proses perawatan dan perbaikan tanki ini disebut dengan proses overhaul tanki. Salah satu kegiatan yang dilakukan dalam proses overhaul tanki adalah fabrikasi plate. Pada PT Pertamina (Persero) RU VI Balongan sendiri tanki minyak yang sedang dilakukan proses fabrikasi adalah tanki 42-T-501A. Tanki tersebut mengalami kebocoran sehingga perlu untuk dilakukan perbaikan dan perawatan. Selama proses fabrikasi plate dilakukan perbaikan dan perawatan pada plate-plate tanki 42-T-501A yang rusak dan kotor. Plate-plate tanki yang rusak dan kotor tersebut dilakukan pengelasan, penghalusan, sandblasting, pengecatan dll untuk menghasilkan plate-plate yang baru untuk dipasang kembali pada tanki. Namun, selama proses fabrikasi tersebut terdapat potensi bahaya yang dapat mengancam kesehatan dan keselamatan pekerja. Berdasarkan Fitriana (2012), pernah terjadi kecelakaan kerja saat proses overhaul tanki di PT Pertamina (Persero) RU III. Selain itu, menurut Diemas (2015), di PT Pertamina (Persero) RU IV juga pernah terjadi kecelakaan kerja saat proses overhaul tanki (cnnindonesia.com). Seperti yang telah diketahui sebelumnya dalam proses overhaul tanki tersebut salah satu proses yang dilakukan didalamnya adalah fabrikasi plate. Sehingga sangat besar kemungkinan dalam proses fabrikasi dapat terjadi kecelakaan serupa yang mengancam kesehatan dan keselamatan pekerja. Ditambah lagi menurut Fitriana (2012), perusahaan yang memiliki tingkat risiko kematian paling tinggi dari perusahaan lainnya adalah perusahaan minyak dan gas. Pernyataan ini diperkuat dengan data menurut SKK Migas (2013) yang mengatakan bahwa pada tahun 2013 telah terjadi kecelakaan kerja di sektor minyak dan gas sebanyak 388 kasus yang terdiri dari 283 kasus kecelakaan ringan, 88 kasus kecelakaan sedang, 12 kasus kecelakaan berat dan 5 kasus kecelakaan fatal. PT Pertamina (Persero) RU VI Balongan sebagai salah satu perusahaan minyak dan gas di Indonesia tentunya juga memiliki potensi risiko kecelakaan yang sama.

Kemudian data dari PT Jamsostek (Persero) juga menunjukkan bahwa kecelakaan kerja yang terjadi di Indonesia selalu meningkat setiap tahunnya. Pada tahun 2007 terdapat 83.714 kasus kecelakaan kerja. Kemudian pada tahun 2008 terdapat 94.736 kasus kecelakaan kerja. Pada tahun 2009 jumlah kasus kecelakaan yang terjadi juga masih tinggi sebanyak 96.314 kasus. Kemudian pada tahun 2010 kasus kecelakaan kerja yang terjadi sebanyak 98.711 kasus dan pada tahun 2011 terdapat kasus kecelakaan sebanyak 99.491 kasus. Sementara pada tahun 2012 menurut Supriyadi (2014), berdasarkan data Jamsostek terdapat 103.000 kejadian kecelakaan. Hingga data terakhir pada tahun 2013 terjadi kasus kecelakaan sebanyak 129.911 kasus. Menurut data kecelakaan tahun 2013 tersebut diketahui 75,8 persen korbannya berjenis kelamin laki-laki dengan rincian sebanyak 3.093 pekerja meninggal dunia, 15.106 pekerja mengalami sakit, 174.266 lukaluka dan sebanyak 446 orang meninggal mendadak (Baihaqi, 2014).

Sebenarnya kecelakaan kerja tersebut dapat dicegah dengan melakukan identifikasi dan penilaian terhadap risiko bahaya pada pekerjaan. Melalui 
identifikasi dan penilaian risiko tersebut dapat diketahui berbagai macam risiko suatu pekerjaan yang kemudian dapat dilakukan berbagai upaya pengendalian untuk mengurangi risiko tersebut agar tidak sampai terjadi kecelakaan. Dengan kata lain Identifikasi bahaya dan penilaian risiko (HIRA) ini dapat dijadikan sebagai dasar tindakan pencegahan dan tindakan penanggulangan potensi bahaya yang mengancam keselamatan dan mengganggu kesehatan para pekerja proses fabrikasi plate tanki 42-T-501A. Oleh karena itu, berdasarkan kebutuhan perusahaan dan potensi bahaya yang dapat terjadi pada proses fabrikasi plate penulis tertarik untuk melakukan penelitian mengenai Hazard Identification and Risk Assessment (HIRA) pada proses fabrikasi plate tanki 42-T-501A milik PT Pertamina (Persero) RU VI Balongan.

Tujuan umum dari penelitian ini adalah melakukan identifikasi bahaya dan penilaian risiko pada proses fabrikasi plate tanki 42-T-501A milik PT Pertamina (Persero) RU VI Balongan. Sedangkan tujuan khusus pada penelitian ini adalah mengidentifikasi bahaya, melakukan penilaian risiko dan menentukan tingkat risiko pada proses fabrikasi plate tanki 42-T-501A milik PT Pertamina (Persero) RU VI Balongan.

\section{METODE}

Jenis dan rancang bangun penelitian ini apabila dilihat berdasarkan waktu penelitian bersifat cross sectional karena proses pengumpulan data dan pengamatan terhadap variabel dilakukan sekaligus atau pada satu waktu tertentu. Sementara apabila dilihat berdasarkan segi tempat, penelitian ini termasuk penelitian lapangan, sebab penelitian yang dilakukan dan cara peneliti dalam mendapatkan data adalah langsung terjun ke lapangan dengan melakukan wawancara, observasi dan pembagian kuesioner baik dengan pekerja maupun pihak K3 perusahaan. Apabila dilihat dari cara pengumpulan datanya, penelitian ini bersifat observasional sebab peneliti memperoleh data melalui pengamatan dan wawancara kepada pekerja dan pihak terkait di perusahaan. Selain itu, objek dalam penelitian ini tidak diberi perlakuan selama penelitian berlangsung hanya diamati/observasional. Berdasarkan sifat masalah dan analisa datanya, penelitian ini termasuk dalam penelitian deskriptif sebab penelitian ini tidak membuat perbandingan atau penghubungan antar variabel. Penelitian ini menggambarkan tentang suatu keadaan secara objektif.
Populasi dalam penelitian ini adalah seluruh pekerja dan safety inspector/petugas K3 pada proses fabrikasi plate tanki 42-T-501A di PT Pertamina (Persero) RU VI Balongan yang berjumlah 20 orang. Penelitian ini menggunakan total populasi sebagai bagian dari penelitian. Penelitian ini dilakukan di PT Pertamina (Persero) RU VI Balongan Jawa Barat khususnya pada bagian fabrikasi plate tanki 42 T-501A yaitu pada Maintanance Area IV unit Oil Movement (OM). Waktu penelitian ini dimulai pada 22 April 2016 sampai dengan 6 Mei 2016.

Variabel yang akan diteliti dalam penelitian ini adalah identifikasi bahaya, penilaian risiko, dan penentuan tingkat risiko pada proses fabrikasi plate tanki 42-T-501A di PT Pertamina (Persero) RU VI Balongan.

Data yang dikumpulkan dalam penelitian ini terdapat dua jenis yaitu data primer dan data sekunder. Data Primer diperoleh melalui observasi dan wawancara. Observasi dan wawancara ini digunakan untuk mengetahui proses kerja fabrikasi plate tanki 42-T-501A, potensi bahaya yang ada, besarnya risiko pekerjaan dan kondisi lingkungan kerjanya. Sementara data sekunder yang dikumpulkan adalah gambaran umum perusahaan, prosedur kerja fabrikasi plate, jumlah pekerja, alat dan bahan berbahaya dalam proses fabrikasi plate serta upaya pengendalian kecelakaan yang telah dilakukan.

Teknik pengolahan dan analisis data yang dilakukan berpedoman pada data hasil observasi dan wawancara. Berdasarkan hasil observasi dan wawancara diketahui potensi bahaya beserta nilai

Tabel 1. Risk Assessment Matrix

\begin{tabular}{|c|c|c|c|c|c|c|}
\hline \multirow{5}{*}{ 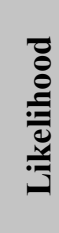 } & 5 & 5 & 10 & 15 & 20 & 25 \\
\hline & 4 & 4 & 8 & 12 & 16 & 20 \\
\hline & 3 & 3 & 6 & 9 & 12 & 15 \\
\hline & 2 & 2 & 4 & 6 & 8 & 10 \\
\hline & 1 & 1 & 2 & 3 & 4 & 5 \\
\hline & & 1 & 2 & 3 & 4 & 5 \\
\hline & & \multicolumn{5}{|c|}{ Severity } \\
\hline
\end{tabular}

Sumber: TKO Penyusunan HIRADC PERTAMINA SAFETY - HSE RU VI Tahun 2016

Kategori Risiko:

\begin{tabular}{|l|l|}
\hline Extreme & $: 15-25$ \\
\hline High Risk & $: 8-2$ \\
\hline Medium Risk & $: 4-6$ \\
\hline Low Risk & $: 1-3$ \\
\hline
\end{tabular}


tingkat peluang (likelihood) dan keparahan (severity) pada proses fabrikasi plate tanki 42-T-501A. Nilai likelihood dan severity pada masing-masing potensi bahaya tersebut dicatat kemudian dianalisis menggunakan tabel risk assessment matrix. Hasil dari analisis ini akan diketahui tingkatan risiko dari masing-masing potensi bahaya apakah bahaya tersebut termasuk risiko rendah (low risk), sedang (medium risk), tinggi (high risk) atau sangat tinggi (extreme). Tingkatan risiko tersebut akan disajikan dalam bentuk diagram pie dan kemudian dinarasikan.

\section{HASIL}

\section{Hazard Identification}

Dalam penelitian ini teknik identifikasi bahaya yang digunakan adalah melalui metode JSA/Job Safety Analisis. Melalui metode JSA akan diketahui semua potensi kejadian berbahaya di setiap langkah kerja yang kemudian dapat ditentukan berbagai tindakan pengendalian yang dibutuhkan untuk mencegah atau mengurangi dampak dari kejadian berbahaya tersebut (Modul HSE Pertamina 05). Selain menggunakan metode JSA, teknik identifikasi bahaya dalam penelitian ini juga dilakukan melalui kegiatan observasi dan wawancara terhadap pihak terkait sebab isi dokumen JSA fabrikasi plate tanki 42-T-501A kurang lengkap dalam menguraikan langkah kerja beserta potensi bahayanya. Oleh karena itu, dilakukan pula wawancara dan observasi untuk melengkapi data dan informasi terkait langkah kerja serta potensi bahaya dalam pekerjaan fabrikasi plate tanki 42-T-501A.

Identifikasi bahaya yang dilakukan mulai dari pekerjaan pengangkatan plate menggunakan crane, cutting torch, pengelasan, grinding, sandblasting dan pengecatan. Hasil identifikasi bahaya menunjukkan dari keenam pekerjaan pada fabrikasi plate tanki 42-T-501A terdapat 24 potensi bahaya dengan 24 risiko didalamnya.

\section{Risk Assessment}

Proses risk assessment/ penilaian risiko dilakukan dengan cara mencari nilai dari risk relative. Risk relative merupakan hasil perkalian antara nilai tingkat keseringan (likelihood) dengan nilai tingkat keparahan (severity) dari masingmasing bahaya. Penentuan besar nilai likelihood dan severity dari masing-masing risiko bahaya dilakukan dengan cara wawancara kepada pekerja dan safety kontraktor fabrikasi plate tanki 42-T501A. Selama proses wawancara, pekerja dan safety kontraktor diberikan tabel berisi skala/ kategori dari likelihood dan severity, sehingga pekerja dan safety kontraktor dapat mengetahui dan menentukan sendiri tingkat kategori dari likelihood dan severity. Skala nilai untuk likelihood adalah 1-5 mulai dari tingkat kemungkinan unlikely hingga almost certain. Sedangkan skala nilai untuk severity adalah 1-5 mulai dari tingkat keparahan insignificant hingga catastrophic. Setelah nilai risk relative didapat kemudian dianalisis menggunakan table Risk Assessment Matrix untuk mengetahui

Tabel 2. Penentuan Peluang (Likelihood)

\begin{tabular}{cl}
\hline Level & \multicolumn{1}{c}{ Deskripsi } \\
\hline 1 & $\begin{array}{l}\text { Tidak pernah terdengar terjadi di industry } \\
\text { serupa di dunia }\end{array}$ \\
\hline 2 & $\begin{array}{l}\text { Pernah terdengar terjadi di industry serupa di } \\
\text { dunia }\end{array}$ \\
\hline 3 & $\begin{array}{l}\text { Pernah terjadi lebih dari } 1 \times \text { pertahun di } \\
\text { industry serupa di dunia atau pernah terjadi di } \\
\text { industry serupa di Indonesia }\end{array}$ \\
\hline 4 & $\begin{array}{l}\text { Pernah terjadi lebih dari 1 } \\
\text { industry serupa di Indonesia atau pernah di } \\
\text { terjadi di RU VI }\end{array}$ \\
\hline 5 & $\begin{array}{l}\text { Pernah terjadi lebih dari } 1 \times \text { pertahun di RU } \\
\text { VI }\end{array}$ \\
\hline
\end{tabular}

Sumber: TKO Penyusunan HIRADC PERTAMINA SAFETY - HSE RU VI Tahun 2016

Tabel 3. Penentuan Keparahan (Severity)

\begin{tabular}{cl}
\hline Level & \multicolumn{1}{c}{ Deskripsi } \\
\hline 1 & $\begin{array}{l}\text { Cidera ringan - Meliputi kasus P3K } \\
\text { atau diperlukan pengobatan medis namun } \\
\text { tidak menyebabkan pembatasan kerja atau } \\
\text { kehilangan jam kerja }\end{array}$ \\
\hline 2 & $\begin{array}{l}\text { Cidera sedang - Memerlukan pengobatan } \\
\text { medis yang menyebabkan pembatasan kerja } \\
\text { atau kehilangan jam kerja } \leq 24 \text { jam }\end{array}$ \\
\hline 3 & $\begin{array}{l}\text { Cidera berat }-1 \text { kasus cidera yang } \\
\text { memerlukan pengobatan medis yang } \\
\text { menyebabkan kehilangan jam kerja } \geq 24 \text { jam } \\
\text { atau ketidakmampuan bekerja sementara }\end{array}$ \\
\hline 4 & $\begin{array}{l}\text { Kejadian fatal - terjadi kasus luka berat atau } \\
\text { menyebabkan 1 kasus cacat permanen atau } \\
\text { kematian }\end{array}$ \\
\hline 5 & $\begin{array}{l}\text { Bencana - Menyebabkan lebih dari 1 kasus } \\
\text { cacat permanen atau kematian }\end{array}$ \\
\hline
\end{tabular}

Sumber: TKO Penyusunan HIRADC PERTAMINA SAFETY - HSE RU VI Tahun 2016 
Tabel 4. Hasil Hazard Identification dan Risk Assessment Proses Fabrikasi Plate Tanki 42-T-501A

\begin{tabular}{|c|c|c|c|c|c|c|}
\hline \multirow[t]{2}{*}{ Activity } & \multirow[t]{2}{*}{ Hazard/ Bahaya } & \multirow[t]{2}{*}{ Risk/ Risiko } & \multirow{2}{*}{$\begin{array}{c}\text { Consequencel } \\
\text { Akibat }\end{array}$} & \multicolumn{3}{|c|}{$\begin{array}{c}\text { Risk Assessment } \\
\text { Matrix }\end{array}$} \\
\hline & & & & $\mathrm{L}$ & $\mathrm{S}$ & $\mathrm{RR}$ \\
\hline $\begin{array}{l}\text { Pekerjaan } \\
\text { mengangkat plate } \\
\text { menggunakan crane }\end{array}$ & a. Plate dapat terjatuh & $\begin{array}{l}\text { Menimpa } \\
\text { pekerja }\end{array}$ & $\begin{array}{l}\text { Patah tulang/ } \\
\text { kematian }\end{array}$ & 2 & 4 & $\begin{array}{c}8 \\
\text { (High risk) }\end{array}$ \\
\hline \multirow{4}{*}{$\begin{array}{l}\text { Pekerjaan } \\
\text { pemotongan dengan } \\
\text { cutting torch }\end{array}$} & a. Tanki oksigen terjatuh & Tertimpa & Memar & 2 & 3 & $\begin{array}{c}6 \\
\text { (Medium risk) }\end{array}$ \\
\hline & b. Cahaya torch & Terpapar cahaya & Iritasi mata & 4 & 2 & $\begin{array}{c}8 \\
\text { (High risk) } \\
\end{array}$ \\
\hline & c. Fume & Terpapar fume & $\begin{array}{l}\text { Infeksi saluran } \\
\text { pernafasan }\end{array}$ & 4 & 2 & $\begin{array}{c}8 \\
\text { (High risk) }\end{array}$ \\
\hline & d. Percikan api & Terpapar panas & $\begin{array}{l}\text { Luka bakar/ } \\
\text { kebakaran }\end{array}$ & 3 & 3 & $\begin{array}{c}9 \\
\text { (High risk) }\end{array}$ \\
\hline \multirow[t]{5}{*}{ Pengelasan } & a. Cahaya las & Terpapar cahaya & Iritasi mata & 4 & 2 & $\begin{array}{c}8 \\
\text { (High risk) }\end{array}$ \\
\hline & b. Fume & Terpapar fume & $\begin{array}{l}\text { Infeksi saluran } \\
\text { pernafasan }\end{array}$ & 4 & 2 & $\begin{array}{c}8 \\
\text { (High risk) } \\
\end{array}$ \\
\hline & c. Percikan api & Terpercik api & $\begin{array}{l}\text { Luka bakar/ } \\
\text { kebakaran }\end{array}$ & 3 & 3 & $\begin{array}{c}9 \\
\text { (High risk) } \\
\end{array}$ \\
\hline & d. Kebisingan & Terpapar bising & $\begin{array}{l}\text { Kemampuan } \\
\text { mendengar berkurang }\end{array}$ & 2 & 1 & $\begin{array}{c}1 \\
(\text { Low risk) }\end{array}$ \\
\hline & e. Aliran listrik & $\begin{array}{l}\text { Tersetrum/ } \\
\text { tersengat listrik }\end{array}$ & $\begin{array}{l}\text { Kejut listrik/ luka } \\
\text { bakar }\end{array}$ & 2 & 3 & $\begin{array}{c}6 \\
\text { (Medium risk) }\end{array}$ \\
\hline \multirow[t]{4}{*}{$\begin{array}{l}\text { Penghalusan dengan } \\
\text { gerinda }\end{array}$} & a. Percikan api & Terpercik api & $\begin{array}{l}\text { Luka bakar/ } \\
\text { kebakaran }\end{array}$ & 3 & 3 & $\begin{array}{c}9 \\
\text { (High risk) }\end{array}$ \\
\hline & b. Aliran Listrik & Tersetrum & $\begin{array}{l}\text { Kejut listrik/luka } \\
\text { bakar }\end{array}$ & 2 & 3 & $\begin{array}{c}6 \\
\text { (Medium risk) }\end{array}$ \\
\hline & c. Pisau mesin gerinda & $\begin{array}{l}\text { Tangan terkena } \\
\text { pisau mesin } \\
\text { gerinda }\end{array}$ & Tergores/terpotong & 3 & 3 & $\begin{array}{c}9 \\
\text { (High risk) }\end{array}$ \\
\hline & d. Kebisingan & Terpapar bising & $\begin{array}{l}\text { Kemampuan } \\
\text { mendengar berkurang }\end{array}$ & 2 & 1 & $\begin{array}{c}1 \\
\text { (Low risk) }\end{array}$ \\
\hline \multirow[t]{4}{*}{ Sandblast plate } & a. Kebisingan & Terpapar bising & $\begin{array}{l}\text { Tuli/ kemampuan } \\
\text { mendengar berkurang }\end{array}$ & 2 & 3 & $\begin{array}{c}6 \\
\text { (Medium risk) }\end{array}$ \\
\hline & b. Debu & Terpapar debu & $\begin{array}{l}\text { Iritasi mata dan } \\
\text { infeksi saluran } \\
\text { pernafasan }\end{array}$ & 3 & 1 & $\begin{array}{c}3 \\
\text { (Low risk) }\end{array}$ \\
\hline & c. Tabung bertekanan tinggi & Pecah/ meledak & Luka/ meninggal & 4 & 3 & $\begin{array}{c}12 \\
\text { (High risk) }\end{array}$ \\
\hline & d. Selang bertekanan tinggi & $\begin{array}{l}\text { Menghantam } \\
\text { pekerja }\end{array}$ & Luka/ meninggal & 4 & 3 & $\begin{array}{c}12 \\
\text { (High risk) } \\
\end{array}$ \\
\hline \multirow[t]{6}{*}{$\begin{array}{l}\text { Pengecatan dengan } \\
\text { kompresor }\end{array}$} & a. Kebisingan & Terpapar bising & $\begin{array}{l}\text { Kemampuan } \\
\text { mendengar berkurang }\end{array}$ & 2 & 1 & $\begin{array}{c}2 \\
\text { (Low risk) }\end{array}$ \\
\hline & b. Aliran listrik & $\begin{array}{l}\text { Tersengat listrik/ } \\
\text { tersetrum }\end{array}$ & $\begin{array}{l}\text { Kejut listrik/ luka } \\
\text { bakar }\end{array}$ & 2 & 3 & $\begin{array}{c}6 \\
\text { (Medium risk) }\end{array}$ \\
\hline & $\begin{array}{l}\text { c. Kabel yang menghalangi } \\
\text { mobilisasi }\end{array}$ & Tersandung & Memar & 3 & 1 & $\begin{array}{c}3 \\
(\text { Low risk) }\end{array}$ \\
\hline & d. Bekerja di ketinggian & Terjatuh & $\begin{array}{l}\text { Patah tulang/ } \\
\text { kematian }\end{array}$ & 4 & 4 & $\begin{array}{c}16 \\
\text { (Extreme) }\end{array}$ \\
\hline & e. Uap Debu cat & $\begin{array}{l}\text { Terpapar } \\
\text { uap cat }\end{array}$ & $\begin{array}{l}\text { Infeksi saluran } \\
\text { pernafasan }\end{array}$ & 3 & 1 & $\begin{array}{c}3 \\
\text { (Low risk) }\end{array}$ \\
\hline & $\begin{array}{l}\text { f. Solven thinner flammable } \\
\text { material }\end{array}$ & $\begin{array}{l}\text { Mudah menyala/ } \\
\text { terbakar }\end{array}$ & Kebakaran & 2 & 3 & $\begin{array}{c}6 \\
\text { (Medium risk) }\end{array}$ \\
\hline
\end{tabular}


tingkatan risikonya. Menurut TKO Penyusunan HIRADC PT PERTAMINA, risiko yang termasuk kedalam kategori low risk adalah risiko dengan nilai risk relative 1-3 sedangkan risiko yang termasuk kedalam ketegori medium risk merupakan risiko dengan nilai risk relative 4-6. Sementara itu risiko yang termasuk kedalam kategori high risk adalah risiko dengan nilai risk relative 8-12 dan risiko yang termasuk kedalam kategori extreme adalah risiko dengan nilai risk relative 15-25.

Berdasarkan hasil proses penentuan tingkat risiko, dari 24 risiko dalam 6 aktivitas proses fabrikasi plate terdapat 6 jenis risiko kategori low risk (25\%), 6 jenis risiko kategori medium risk (25\%), 11 risiko kategori high risk (45\%) dan 1 risiko kategori extreme (5\%).

\section{PEMBAHASAN}

\section{Hazard Identification}

\section{Pengangkatan Plate Menggunakan Crane}

Tahap awal pada proses fabrikasi plate adalah mengangkat keluar plate-plate rusak di dalam tanki untuk diperbaiki. Pengangkatan plate tanki tersebut menggunakan bantuan alat angkat crane.

Pada proses pengangkatan plate menggunakan crane tersebut terdapat bahaya yang mengancam kesehatan dan keselamatan pekerja. Bahaya yang mungkin saja terjadi adalah terjatuhnya plate tanki. Bahaya terjatuhnya plate tanki ini dapat mengakibatkan patah tulang bahkan kematian pada pekerja yang tertimpa plate tanki. Bahaya terjatuhnya plate tanki termasuk dalam kategori bahaya mekanik (Ramli, 2010). Bahaya ini termasuk dalam kategori bahaya mekanik sebab bahaya tersebut disebabkan oleh mesin atau alat kerja mekanik yaitu crane. Dalam proses pengangkatan plate menggunakan crane, bahaya terjatuhnya plate dapat terjadi apabila plate tidak terikat dengan kuat pada hook dari crane. Selain itu terjatuhnya plate tanki juga dapat terjadi apabila sling crane terputus. Oleh karena itu, sebelum crane digunakan perlu dilakukan pemeriksaan untuk mengetahui kondisi dari crane. Sehingga saat digunakan, crane tersebut dapat berfungsi dengan baik dan tidak menimbulkan celaka.

\section{Pemotongan Menggunakan Cutting Torch}

Pada pekerjaan fabrikasi plate terdapat aktivitas pemotongan plate menggunakan cutting torch. Aktivitas pemotongan plate menggunakan cutting torch ini terdapat beberapa potensi bahaya yang mengancam keselamatan dan kesehatan pekerja seperti terjatuhnya tanki oksigen, paparan cahaya torch, paparan fume dan percikan api.

Terjatuhnya tanki oksigen disebabkan oleh peletakan tabung oksigen yang tidak kuat dan tidak diikat. Apabila tabung oksigen ini terjatuh, tabung oksigen tersebut dapat mengenai/menghantam pekerja yang berada disekitar area kerja. Akibatnya akan timbul memar/luka pada tubuh pekerja. Menurut Heinrich (1980), penyebab terjadinya bahaya ini digolongkan sebagai kecelakaan kerja unsafe action. Bahaya ini termasuk dalam kategori unsafe action sebab terjatuhnya tanki tersebut dikarenakan tindakan manusia/pekerja yang membahayakan diri sendiri dan orang lain. Pekerja harus memastikan telah meletakkan dan mengikat tanki oksigen dengan benar dan kuat agar bahaya terjatuhnya tanki oksigen tidak terjadi.

Bahaya lain yang teridentifikasi pada pekerjaan pemotongan plate menggunakan cutting torch adalah bahaya paparan torch. Pada saat terjadi pemotongan plate menggunakan cutting torch akan muncul cahaya torch yang cukup menyilaukan. Apabila frekuensi dan intensitas paparan cahaya torch terlalu tinggi dapat mengakibatkan iritasi mata pada pekerja. Selain paparan cahaya, saat melakukan pemotongan plate menggunakan cutting torch juga akan timbul fume/ asap. Paparan fume ini juga dapat memberikan efek negative pada pekerja apabila frekuensi dan intensitasnya terlalu tinggi. Paparan fume ini dapat mengakibatkan infeksi saluran pernafasan pada pekerja. Menurut Tualeka (2013), paparan cahaya dan paparan fume cutting torch merupakan bahaya kesehatan kerja jenis bahaya fisik. Dikatakan bahaya fisik sebab paparan cahaya dan fume cutting torch tersebut berada di sekitar lingkungan kerja fisik pekerja. Paparan cahaya dan fume tersebut masuk kedalam tubuh pekerja yang kemudian dapat menimbulkan gangguan kesehatan.

Paparan cahaya yang keluar akibat aktivitas pemotongan plate menggunakan cutting torch biasanya bersamaan dengan keluarnya percikan api. Menurut Tualeka (2013), percikan api tersebut termasuk dalam kategori bahaya keselamatan kerja jenis kebakaran. Percikan api tersebut apabila mengenai tubuh pekerja dapat mengakibatkan luka bakar. Selain itu apabila percikan api tersebut mengenai bahan mudah terbakar (flammable) dan bahan mudah meledak (explosive) dapat menimbulkan kebakaran dan ledakan di tempat kerja. Oleh karena itu, saat pekerjaan pemotongan 
menggunakan cutting torch perlu untuk memastikan bahwa area di sekitar pemotongan tidak terdapat bahan mudah terbakar (flammable) dan bahan mudah meledak (explosive) untuk mencegah terjadinya kebakaran.

\section{Pengelasan}

Hasil observasi dan wawancara pada proses pengelasan tanki 42-T-501A menunjukkan dalam pekerjaan tersebut terdapat berbagai potensi bahaya yang mengancam kesehatan dan keselamatan pekerja. Pada saat pekerja melakukan pengelasan untuk menghubungkan antar plate, akan timbul cahaya dari proses pengelasan. Paparan cahaya ini cukup menyilaukan apabila mengenai mata pekerja (Siswanto, 1994). Sinar yang tampak secara kasat mata, masuk melalui kornea sampai ke retina seperti apa adanya, sehingga paparan berlebihan dan dalam jangka waktu lama dapat menyebabkan kelelahan mata (Daryanto, 2012). Bahaya ini akan lebih berisiko apabila pekerja tidak menggunakan APD untuk melindungi diri dari paparan cahaya las ini. Apabila pekerja melakukan pengelasan tanpa menggunakan APD yaitu faceshield/ cup las paparan cahaya las yang diterima akan langsung mengenai kornea sampai ke retina sehingga risiko kelelahan mata akibat paparan cahaya las akan lebih besar.

Selain paparan cahaya, dalam pekerjaan pengelasan akan timbul pula fume/asap dari proses pengelasan. Fume merupakan partikel kecil yang berukuran kurang dari 1 mikron yang berasal dari uap logam. Uap logam tersebut mengalami proses oksidasi serta kondensasi dalam udara sehingga terbentuk oksida logam tersebut (Siswanto, 1994). Paparan fume ini dapat mengakibatkan infeksi saluran pernafasan pada pekerja dan merupakan bahaya kesehatan kerja jenis bahaya kimia (Tualeka, 2013).

Pada pekerjaan pengelasan, selain menimbulkan cahaya dan fume akan timbul pula percikan api. Bahaya percikan api ini menurut Tualeka (2013) merupakan kategori bahaya keselamatan kerja jenis kebakaran. Bahaya percikan api ini termasuk dalam jenis bahaya kebakaran sebab apabila percikan api tersebut mengenai bahan yang mudah terbakar (flammable) dan mudah meledak (explosive) percikan api tersebut dapat menyebabkan kebakaran dan ledakan. Selain itu percikan api ini dapat mengakibatkan luka bakar apabila mengenai tubuh pekerja.

Saat proses pengelasan terjadi pula gesekan antara mesin las dengan plate tanki. Suara yang dihasilkan dari gesekan tersebut termasuk dalam kategori kebisingan (Siswanto, 1994). Paparan bising ini apabila terjadi dalam waktu yang lama dapat mengakibatkan ketulian/ berkurangnya kemampuan mendengar para pekerja.

Bahaya selanjutnya yang teridentifikasi pada proses pengelasan adalah bahaya tersetrum. Mesin las dapat menyala dengan menggunakan listrik sebagai sumber energi. Arus yang digunakan untuk pengelasan berkisar 80-200 Ampere (Dwi dan Sulaksmono, 2013). Saat mengalirkan listrik sebagai sumber energi pada mesin las, pekerja dapat mengalami tersetrum yang berakibat kejut listrik bahkan luka bakar. Bahaya ini menurut Ramli (2010) termasuk dalam kategori bahaya listrik. Risiko bahaya ini akan lebih besar apabila saat pengaturan besar arus listrik pada motor las, pekerja tidak menggunakan sarung tangan. Selain itu kondisi pelindung pesawat las yang sudah aus/memudar juga meningkatkan risiko bahaya tersetrum pada pekerja.

\section{Grinding}

Dalam proses fabrikasi plate tanki $42-\mathrm{T}$ $501 \mathrm{~A}$, grinding dibutuhkan untuk menghaluskan permukaan plate agar plate terbentuk sempurna untuk dipasang kembali ke dalam tanki (Andhini, Sugiono dan Remba, 2015). Pada pekerjaan gerinda tersebut teridentifkasi empat potensi bahaya yang dapat mengancam kesehatan dan keselamatan pekerja yaitu percikan api, tersetrum, tergores pisau mesin gerinda dan kebisingan.

Selama proses penggunaan mesin gerinda akan muncul percikan api akibat gesekan antara mesin gerinda dengan plate-plate dari tanki. Percikan api tersebut merupakan bahaya keselamatan kerja dengan jenis kebakaran menurut Tualeka (2013). Percikan api mesin gerinda tersebut termasuk dalam bahaya jenis kebakaran sebab apabila percikan api tersebut mengenai benda yang mudah terbakar (flammable) dan mudah meledak (explosive) percikan api tersebut dapat menimbulkan kebakaran dan ledakan. Selain itu, apabila percikan api tersebut mengenai kulit pekerja dapat menimbulkan luka bakar pada kulit pekerja. Oleh karena itu, saat proses grinding pekerja diwajibkan memakai coverall/APD untuk melindungi dirinya dari percikan api gerinda. Kondisi sekitar proses grinding juga harus dipastikan bebas dari material explosive dan flammable untuk menghindari terjadinya kebakaran.

Bahaya tersetrum bersumber dari aliran listrik yang digunakan untuk menyalakan mesin 
gerinda. Menurut Tualeka (2013) bahaya tersetrum merupakan bahaya keselamatan jenis bahaya elektrik. Aliran listrik tersebut dapat membahayakan pekerja apabila pekerja kurang berhati-hati dan tidak menggunakan sarung tangan saat mengalirkan listrik. Selain itu kondisi kabel yang sudah rusak/ terkelupas juga memperbesar risiko tersetrum yang dapat berakibat luka bakar dan kejut listrik.

Dalam pekerjaan menggunakan gerinda ini teridentifikasi pula adanya bahaya mekanis. Bahaya mekanis adalah bahaya yang bersumber dari peralatan mekanis/ benda bergerak yang digerakkan secara manual maupun dengan penggerak (Ramli 2011). Bahaya mekanis pada pekerjaan gerinda ini terdapat pada putaran pisau mesin gerinda. Putaran pisau mesin gerinda tersebut dapat menimbulkan goresan bahkan dapat memotong tangan pekerja.

Selain bahaya mekanis, putaran dari mesin gerinda yang sedang menyala tersebut akan menimbulkan suara-suara yang termasuk dalam kategori kebisingan. Paparan bising yang berlebih dan terus menerus dari mesin gerinda ini dapat mengakibatkan ketulian/ berkurangnya kemampuan mendengar pada pekerja.

\section{Sandblasting}

Sandblasting dalam proses fabrikasi plate bertujuan untuk membersihkan plate dari debu dan karat sebelum dicat dan dipasang kembali ke dalam tanki. Pada proses sandblasting ini diketahui terdapat potensi bahaya yang dapat mengancam kesehatan dan keselamatan pekerja. Saat mesin sandblast dihidupkan/ bekerja, suara yang dihasilkan dari mesin sandblast ini sangat keras dan termasuk dalam kategori kebisingan. Paparan bising dari mesin sandblast tersebut berisiko menimbulkan ketulian/ berkurangnya kemampuan dengar para pekerja. Bahaya ini merupakan bahaya kesehatan kerja dengan jenis bahaya fisik (Tualeka, 2013).

Bahaya selanjutnya yang teridentifikasi adalah bahaya paparan debu. Sand/ pasir merupakan bahan utama yang digunakan dalam proses sandblast. Pasir tersebut akan disemprotkan dengan tekanan yang tinggi ke arah plate sehingga karat dan kotorankotoran yang ada pada plate dapat menghilang. Akibat semprotan sand/ pasir itulah selama proses sandblast banyak terdapat paparan debu yang berasal dari pasir/sand yang digunakan tersebut. Paparan debu ini apabila mengenai pekerja dapat berisiko terjadi iritasi mata dan infeksi saluran pernafasan.

Alat-alat dalam proses sandblasting juga dapat menimbulkan celaka bagi para pekerjanya. Salah satu komponen alat yang digunakan dalam proses sandblast plate adalah tabung dengan tekanan tinggi. Tabung dengan tekanan tinggi ini harus selalu dirawat dan dicek kondisinya agar tidak menimbulkan bahaya bagi pekerja sebab dalam penggunaannya terdapat risiko pecah/meledaknya tabung bertekanan tersebut. Pecah/meledaknya tabung bertekanan tersebut dapat melukai bahkan menyebabkan kematian bagi pekerja.

Selain tabung bertekanan, dalam proses sandblast terdapat selang yang memiliki tekanan tinggi pula. Selang ini berfungsi saat proses penyemprotan sand/ pasir kearah plate. Seperti halnya tabung bertekanan, kondisi selang bertekanan tersebut juga perlu mendapat perhatian dan perawatan agar tidak menimbulkan bahaya bagi pekerja. Apabila selang bertekanan tersebut kondisi dan penggunaannya tidak dalam keadaan baik, selang tersebut dapat lepas dan menghantam tubuh pekerja. Hantaman selang tersebut dapat melukai pekerja bahkan dapat menimbulkan kematian.

\section{Pengecatan Menggunakan Kompresor}

Setelah plate tanki selesai dipotong, dibentuk dan dibersihkan tahap terakhir pada proses fabrikasi plate tanki 42-T-501A adalah melakukan pengecatan. Proses pengecatan dilakukan dengan menggunakan kompresor. Berdasarkan hasil identifikasi bahaya, pada proses pengecatan dengan menggunakan kompresor tersebut terdapat enam potensi bahaya yaitu kebisingan, tersengat listrik, tersandung kabel, terjatuh dari ketinggian, paparan uap cat dan terbakar.

Bahaya kebisingan berasal dari suara yang dihasilkan dari mesin kompresor. Apabila frekuensi dan intensitas bising ini tinggi, paparan bising ini dapat mengakibatkan ketulian/berkurangnya kemampuan mendengar pada pekerja. Bahaya ini termasuk dalam kategori bahaya kesehatan kerja jenis bahaya fisik (Tualeka, 2013). Risiko ketulian dari bahaya kebisingan ini dapat meningkat apabila pekerja tidak menggunakan earplug/APD saat melakukan pengecatan. Pekerja yang tidak menggunakan earplug/APD saat proses pengecatan tidak terlindungi dari paparan bising yang tinggi sehingga rambatan suara bising tersebut dapat masuk ke lubang telinga dan merusak gendang telinga.

Bahaya tersengat listrik berasal dari sumber energi yang digunakan mesin kompresor untuk dapat menyala. Menurut Ramli (2011) bahaya ini termasuk dalam kategori bahaya elektrik di mana bahaya disebabkan oleh peralatan yang mengandung arus 
listrik. Berdasarkan hasil identifikasi, potensi bahaya muncul saat pekerja mengalirkan listrik kedalam mesin kompresor. Apabila saat mengalirkan listrik tersebut pekerja tidak menggunakan sarung tangan, pekerja dapat tersetrum/tersengat listrik. Selain itu kondisi kabel yang rusak/terkelupas juga dapat meningkatkan risiko tersetrum/tersengat listrik. Sengatan listrik tersebut dapat berakibat kejut listrik dan luka bakar.

Bahaya lain yang teridentifikasi adalah bahaya tersandung. Saat proses pengecatan terdapat banyak kabel yang berserakan di sekitar area kerja. Kondisi kabel yang berserakan ini dapat menghalangi mobilitas para pekerja. Sehingga dapat berisiko tersandung yang berakibat memar pada tubuh pekerja.

Pada proses pengecatan teridentifikasi pula adanya bahaya kimia. Bahaya kimia tersebut berasal paparan uap cat dari cat yang digunakan. Paparan uap tersebut dapat berisiko terjadinya infeksi pada saluran pernafasan pekerja. Menurut Tualeka (2013), konsentrasi uap ini termasuk dalam kategori bahaya kesehatan kerja jenis bahaya kimia. Selain bahaya kimia, teridentifikasi pula adanya bahaya ledakan dan kebakaran. Bahaya ledakan dan kebakaran bersumber dari thinner yang digunakan selama proses pengecatan, Thinner merupakan jenis material flammable atau bahan yang mudah menyala. Sehingga selama proses pengecatan terdapat potensi bahaya terjadinya kebakaran.

\section{Risk Assessment}

Berdasarkan hasil penilaian risiko diketahui pada proses fabrikasi plate tanki 42-T-501A terdapat empat jenis risiko mulai dari low risk (25\%), medium risk (25\%), high risk (45\%) dan extreme (5\%). Menurut Ramli (2011) pada konsep ALARP, risiko yang termasuk dalam kategori risiko tinggi (high risk) dan sangat tinggi (extreme) merupakan risiko yang tidak dapat diterima. Risiko ini perlu untuk dilakukan langkah pencegahan dan pengurangan tingkat risiko sampai pada batas yang dapat diterima. Risiko dalam proses fabrikasi plate tanki 42-T-501A yang termasuk dalam kategori risiko tinggi (high risk) dan sangat tinggi (extreme) adalah sebagai berikut:

\section{High Risk}

\section{Aktivitas Pengangkatan Plate dengan Crane.}

Bahaya yang ditimbulkan dari aktivitas ini adalah terjatuhnya plate sehingga dapat menimpa pekerja yang sedang bekerja dibawahnya. Apabila plate tersebut terjatuh dan menimpa pekerja, dampak/akibat yang ditimbulkan adalah patah tulang bahkan kematian. Kategori dampak yang ditimbulkan tersebut termasuk dalam kategori cidera berat sehingga nilai severitynya sebesar 3 . Sementara itu berdasarkan hasil wawancara dikatakan bahwa kemungkinan pekerja tertimpa plate termasuk dalam kategori unlikey (jarang terjadi) sehingga nilai likelihoodnya sebesar 2. Berdasarkan nilai severity dan likelihood tersebut risiko patah tulang/kematian akibat tertimpa plate yang terjatuh termasuk dalam kategori risiko tinggi/high risk. Saloni dan Ferida (2016), juga mengatakan bahwa aktivitas pengangkatan plate menggunakan crane merupakan pekerjaan dengan risiko bahaya tinggi.

\section{Paparan Cahaya Torch Cutting Torch}

Pada pekerjaan pemotongan plate dengan cutting torch terdapat risiko bahaya paparan cahaya torch. Pekerja yang terpapar cahaya torch saat melakukan pemotongan plate dapat terjadi iritasi mata. Berdasarkan hasil wawancara, para pekerja mengatakan bahwa mereka merasakan kesulitan membuka mata/ mata terasa pedih apabila terpapar oleh cahaya torch. Dampak tersebut termasuk dalam kategori cidera sedang sehingga nilai severitynya sebesar 2. Sekalipun dampak yang ditimbulkan termasuk dalam kategori cidera sedang, berdasarkan hasil wawancara diketahui kemungkinan terjadinya paparan tersebut sangat besar. Para pekerja mengaku sering mengalami hal tersebut. Nilai likelihoodnya termasuk dalam kategori likely (sering) sehingga nilai likelihoodnya sebesar 4. Berdasarkan nilai severity dan likelihood tersebut, risiko iritasi mata akibat paparan cahaya torch saat pemotongan plate termasuk dalam kategori risiko tinggi / high risk.

\section{Paparan Fume Cutting Torch}

Dalam aktivitas pemotongan plate menggunakan cutting torch, selain terdapat bahaya paparan torch juga terdapat bahaya paparan fume/asap. Fumel asap tersebut apabila terhirup oleh pekerja dapat 
menimbulkan infeksi pada saluran pernafasan. Berdasarkan hasil wawancara dikatakan pekerja akan mengalami sesak nafas apabila terpapar oleh fume/asap dari proses cutting torch tersebut. Dampak paparan fume ini menurut risk assessment matrix termasuk cidera sedang sehingga nilai severitynya sebesar 2 . Sekalipun, dampak yang ditimbulkan termasuk dalam kategori cidera sedang, kemungkinan terjadinya paparan termasuk dalam kategori likely (sering) sehingga nilai likelihood sebesar 4. Berdasarkan nilai severity dan likelihood tersebut, risiko infeksi saluran pernafasan akibat paparan fume saat pemotongan plate menggunakan cutting torch termasuk dalam kategori risiko tinggi/ high risk.

\section{Percikan Api Cutting torch}

Selain paparan fume dan cahaya, dalam aktivitas pemotongan plate menggunakan cutting torch juga terdapat potensi bahaya percikan api. Apabila pekerja terpercik api akibat proses pemotongan cutting torch tersebut, risiko yang ditimbulkan dapat berupa luka bakar bahkan dapat terjadi kebakaran. Kategori dampak yang ditimbulkan menurut risk assessment matrix termasuk dalam kategori cidera berat, sehingga nilai severitnya sebesar 3. Sementara itu, kemungkinan terjadinya percikan api cutting torch termasuk dalam kategori possible (mungkin terjadi) sehingga nilai likelihoodnya sebesar 3 . Berdasarkan nilai severity dan likelihood tersebut, risiko terbakar akibat percikan api saat pemotongan plate menggunakan cutting torch termasuk dalam kategori risiko tinggi/ high risk.

\section{Paparan Cahaya Pengelasan}

Berdasarkan hasil identifikasi bahaya, diketahui pada pekerjaan pengelasan terdapat risiko paparan cahaya yang dapat mengenai pekerja. Dampak yag ditimbulkan akibat paparan cahaya pengelasan tersebut adalah pekerja dapat mengalami iritasi mata. Berdasarkan hasil wawancara dikatakan pekerja merasakan pedih pada matanya setelah terpapar cahaya dari pengelasan. Menurut risk assessment matrix kategori dampak tersebut termasuk dalam kategori cidera sedang sehingga nilai severitynya sebesar 2. Sekalipun dampak yang ditimbulkan termasuk dalam kategori cidera sedang, berdasarkan hasil wawancara diketahui kemungkinan terjadinya paparan tersebut sangat besar. Para pekerja mengaku sering mengalami hal tersebut sehingga nilai likelihood dari risiko tersebut termasuk dalam kategori likely (sering) dan nilai likelihoodnya sebesar 4. Berdasarkan nilai severity dan likelihood tersebut, risiko iritasi mata akibat paparan cahaya pengelasan termasuk dalam kategori risiko tinggi/ high risk.

\section{Paparan Fume Pengelasan}

Berdasarkan hasil identifikasi bahaya diketahui selain paparan cahaya pengelasan, pada saat pekerjaan pengelasan terdapat pula potensi paparan fume atau asap yang dapat terhirup oleh pekerja. Apabila pekerja menghirup fume atau asap dari pengelasan tersebut risiko yang dapat ditimbulkan adalah infeksi saluran pernafasan. Banyak pekerja yang mengeluhkan sesak nafas setelah melakukan pekerjaan pengelasan. Menurut risk assessment matrix kategori dampak yang ditimbulkan akibat paparan fume pengelasan tersebut termasuk dalam kategori cidera sedang sehingga nilai severitynya sebesar 2. Walaupun dampak yang ditimbulkan termasuk cidera sedang, kemungkinan paparan fume terhadap pekerja termasuk dalam kategori likely (sering) sehingga nilai likelihoodnya sebesar 4. Berdasarkan nilai severity dan likelihood tersebut, risiko infeksi saluran pernafasan akibat paparan fume saat pengelasan termasuk dalam kategori risiko tinggi/ high risk.

\section{Percikan Api Pengelasan}

Selain paparan cahaya dan fume, dalam pekerjaan pengelasan juga terdapat potensi bahaya terpercik api pengelasan. Dampak yang timbul akibat percikan api tersebut adalah pekerja dapat mengalami luka bakar bahkan dapat terjadi kebakaran. Kategori dampak yang demikian menurut risk assessment matrix termasuk dalam kategori cidera berat sehingga nilai severitynya sebesar 3 . Sementara kemungkinan terjadi atau terpaparnya pekerja terhadap percikan api termasuk dalam kategori possible (mungkin terjadi) sehingga nilai likelihoodnya sebesar 3. Berdasarkan nilai severity dan likelihood tersebut, risiko terjadinya luka bakar/ kebakaran akibat percikan api pengelasan termasuk dalam kategori risiko tinggi/ high risk.

\section{Bahaya Tabung dan Selang Bertekanan Proses Sandblasting}

Tabung dan selang bertekanan merupakan salah satu komponen alat yang digunakan dalam proses sandblast. Tabung dan selang tersebut memiliki tekanan yang tinggi sebab digunakan untuk menyemprotkan sand/ pasir ke arah plate agar plate 
menjadi bersih. Tabung dan selang ini harus selalu dicek kondisinya baik setelah pemakaian maupun sebelum pemakaian. Berdasarkan hasil identifikasi tabung dan selang yang bertekanan tinggi ini dapat mengalami ledakan apabila tekanannya berlebihan. Selain itu ledakan juga dapat terjadi apabila kondisi tabung dan selang tidak dalam keadaan baik dan kuat. Ledakan dari tabung dan selang proses sandblast tersebut dapat menciderai bahkan dapat menyebabkan pekerja meninggal dunia. Menurut kategori dalam risk assessment matrix, cidera yang ditimbulkan akibat ledakan tabung dan selang bertekanan tinggi tersebut termasuk dalam kategori cidera berat sehingga nilai severitynya sebesar 3. Sementara itu nilai kemungkinan terjadinya termasuk dalam kategori sering (likely) sehingga nilai likelihoodnya sebesar 4. Berdasarkan nilai severity dan likelihood tersebut, bahaya ledakan dari tabung dan selang bertekanan tinggi saat proses sandblasting termasuk dalam kategori risiko tinggi (high risk).

\section{Extreme}

\section{Terjatuh Saat Bekerja di Ketinggian}

Pekerjaan di ketinggian dalam proses fabrikasi plate tanki 42-T-501A dapat ditemukan pada aktivitas pengecatan plate. Pekerjaan ini termasuk dalam kategori risiko sangat tinggi (extreme) sebab dampak/ konsekuensi yang timbul apabila risiko ini terjadi adalah pekerja dapat terjatuh sehingga menyebabkan patah tulang bahkan dapat terjadi kematian. Oleh karena itulah, nilai severity/ dampak untuk risiko ini menurut risk assessment matrix adalah 3. Sementara itu, nilai likelihood atau kemungkinan terjadinya juga cukup tinggi. Nilai kemungkinan terjatuhnya pekerja saat bekerja diketinggian termasuk dalam kategori likely atau sering sehingga nilai likelihoodnya sebesar 4 . Berdasarkan nilai severity dan likelihood tersebut, risiko terjatuhnya pekerja dari ketinggian termasuk dalam kategori risiko sangat tinggi (extreme).

\section{SIMPULAN}

Bahaya yang teridentifikasi pada proses fabrikasi plate tanki 42-T-501A terdapat 24 potensi bahaya dengan 24 risiko dari 6 aktivitas pekerjaan yang meliputi pekerjaan pengangkatan plate menggunakan crane, cutting torch, pengelasan, grinding, sandblasting dan pengecatan.
Berdasarkan hasil penilaian risiko, dari 24 risiko dalam 6 aktivitas pekerjaan proses fabrikasi plate tanki 42-T-501A terdapat 6 jenis risiko kategori low risk, 6 jenis risiko kategori medium risk, 11 risiko kategori high risk dan 1 risiko kategori extreme. Sementara tingkatan risikonya dari 24 risiko pada proses fabrikasi plate tanki 42-T-501A sebesar 25 $\%$ low risk, $25 \%$ medium risk, $45 \%$ high risk dan $5 \%$ extreme.

\section{DAFTAR PUSTAKA}

Ambarani, A. Y. 2016. Analisis Risiko Pada Proses Overhaul Tanko di PT Pertamina (Persero) Refinery Unit VI Balongan Jawa Barat. Skripsi. Surabaya; Universitas Airlangga.

Andhini D.P., Sugiono., Remba Y.E. 2015. Implementation of Job Safety Analysis (JSA) in Prevention Work Accident (Case Study: PT. Adi Putro Wirasejati). Jurnal Rekayasa dan Manajemen Sistem Industri, Vol. 3, No. 2: 386-396.

Baihaqi, R. 2014. Data Kecelakaan 2013 MenurutJamsostek.http://ekbis.sindonews.com/ $\mathrm{read} / 836859 / 34 / 192-911$-peserta-jamsostekalami-kecelakaan-kerja-1392713047 [22 November 2015]

Daryanto. 2012. Teknik Las. Alfabeta,cv. Bandung.

Diemas. 2015. Kecelakaan Overhaul Tanki PT Pertamina Cilacap. http://www.cnnindonesia. com/ekonomi/20150501193707-85-50581/1orang-tewas-dalam-insiden-kerja-di-kilangpertamina/ [22 November 2015]

Dwi S.B., M. Sulaksmono. 2013. Risk Assessment Pada Pekerjaan Welding Confined Space di Bagian Ship Building PT Dok dan Perkapalan Surabaya. The Indonesian Journal of Occupational Safety and Health, Vol. 2, No. 1 Jan-Jun 2013: 52-60.

Fitriana, R. 2012. Kajian Risiko Keselamatan Kerja Pada Proses Overhaul Tanki Timbun L3 di PT. Pertamina (Persero) RU III Plaju - Sungai Gerong Palembang Tahun 2011. Skripsi. Jakarta; Universitas Indonesia: 3-34.

Heinrich H.W Industrial Accident Prevention. New York: McGraw-Hill Book Company, 1980.

Kementerian Energi dan Sumber Daya Mineral.2012. Kajian Supply Demand Energy. [online] Dari: http://prokum.esdm.go.id/Publikasi/Hasil\%20 Kajian/ESDM\%20SDE.pdf [22 November 2015] 
Modul Sertifiksi SI, GSI \& AT PT. PERTAMINA PERSERO tentang Identifikasi Bahaya, HSE Corporate. 2010.

Occupational Health \& Safety Standard 18001 Tahun 2007 tentang Sistem Manajemen Keselamatan dan Kesehatan Kerja-Persyaratan.

PT Jamsostek (Persero). 2012. Himpunan Peraturan Perundangan Pemerintah Republik Indonesia Mengenai Jaminan Sosial Tenaga Kerja: Jakarta.

PT. Pertamina. 2012. Unit Refinery. http://www. pertamina.com/en/our-business/downstream/ refinery/ [22 November 2015]

Ramli, S. 2011. Pedoman Praktis Manajemen Risiko Dalam Perspektif K3 OHS Risk Management. Jakarta: Dian Rakyat.

Saloni Waruwu dan Ferida Yuamita. 2016. Analisis Faktor Kesehatan dan Keselamatan Kerja (K3) yang Signifikan Memengaruhi Kecelakaan Kerja
Pada Proyek Pembangunan Apartemen Student Castle. Jurnal Spektrum Industri, Vol. 14, No. 1: 1-108.

Siswanto, A. 1994. Bahaya Proses Pengelasan. Surabaya: 2-38. (sitasi tanggal 3 November 2014)

SKK MIGAS. 2014. Sustainability Reporting. [online] Dari: http://www.skkmigas.go.id/wpcontent/uploads/2014/12/SUSTAINABILITYREPORTING-G4.pdf [22 November 2015]

Supriyadi, A. 2014. Data Kecelakaan 2012 MenurutJamsostek.http://katigaku. com/2014/08/24/infografik-data-dan-faktakeselamatan-dan-kesehatan-kerja-di-indonesia/ [22 November 2015]

TKO HIRADC PERTAMINA SAFETY - HSE RU VI Tahun 2016.

Tualeka, A. R. 2013. Analisis Risiko. Surabaya: Graha Ilmu Mulia. 